\title{
Adjustment to chronic obstructive pulmonary disease: the importance of psychological factors
}

\author{
H.C.F. McCathie*, S.H. Spence ${ }^{\#}$, R.L. Tate
}

\begin{abstract}
Adjustment to chronic obstructive pulmonary disease: the importance of psychological factors. H.C.F. McCathie, S. H. Spence, R.L. Tate. (C) ERS Journals Ltd 2002.

ABSTRACT: Research has indicated a weak relationship between the degree of physical problems and quality of life in patients with chronic obstructive pulmonary disease (COPD). The importance of adaptive psychological functioning to maintain optimum quality of life has long been recognized, but there is a lack of empirical evidence concerning the nature of psychological factors involved in adjustment to COPD.

Ninety-two males completed questionnaires to determine their coping strategies, levels of self-efficacy of symptom management and social support. Adjustment was measured in terms of depression, anxiety and quality of life. Symptom severity, socioeconomic status, duration of disease and age, which have been demonstrated to be of consequence in COPD, were used as control variables in hierarchical multiple regression analyses.

Higher levels of catastrophic withdrawal coping strategies and lower levels of selfefficacy of symptom management were associated with higher levels of depression, anxiety and a reduced quality of life. Higher levels of positive social support were linked to lower levels of depression and anxiety, while higher levels of negative social support were linked to higher levels of depression and anxiety.

To maximize quality of life in patients with chronic obstructive pulmonary disease, psychological factors need to be carefully assessed and addressed. Eur Respir J 2002; 19: 47-53.
\end{abstract}

\begin{abstract}
*Dept of Psychology, Concord Repatriation General Hospital, NSW, Australia, " School of Psychology, University of Queensland, Brisbane, Queensland, Australia and "Rehabilitation Studies Unit, Dept of Medicine, University of Sydney, NSW, Australia.

Correspondence: H. McCathie, Dept of Psychology, Concord Repatriation General Hospital, Hospital Road, Concord, NSW, Australia.

Fax: 61297678445
\end{abstract}

Keywords: Adjustment chronic obstructive pulmonary disease psychological factors quality of life

Received: April 262001

Accepted after revision September 17 2001
Chronic obstructive pulmonary disease (COPD) is a major cause of morbidity and it appears that a variety of psychological factors may influence the quality of life of these patients, over and above the extent of physical problems. During the illness COPD patients may experience gross difficulties in their emotional functioning, sleep and rest, physical mobility, social interaction, activities of daily living, recreation, work and finance. It is generally accepted that patients with COPD frequently suffer from depression and anxiety [1], and have a reduced quality of life [2]. The more extensive work in other chronic illnesses, such as rheumatoid arthritis, cancer and chronic pain, has demonstrated that coping strategies, self-efficacy and social support predict adjustment to illness. The small number of studies investigating the relationship between psychological variables and indices of adjustment for patients with COPD, suggest that the role of coping strategies [3], levels of self-efficacy [4] and social support [5], in predicting adjustment warrants further investigation.

LAZARUS and FolKMAN [6] propose a cognitively oriented theory of stress and coping, which has had a great impact on the chronic illness literature. Coping refers to the constantly changing cognitive and behavioural efforts to master, reduce or tolerate the internal and/or external demands that are created by a stressful situation. Importantly, coping refers to efforts to manage demands, regardless of the success of these efforts.

Self-efficacy theory maintains that all processes of psychological change operate through the alteration of the individual's sense of personal mastery or efficacy [7]. According to this theory, psychological changes achieved through different methods and techniques can be explained and predicted by an evaluation of changes in the individual's expectations of self-efficacy. That is, the extent of the belief that one is, or is not capable of performing a particular behaviour, or a set of behaviours.

Social support is another resource that may be used by individuals in their attempt to cope with problems. Social-support research has primarily focused on the positive consequences of social support and interactions, even though the social exchange theorists [8] emphasize that social interactions involve both benefits and costs. Social interactions themselves are not always positive and the consequences of social interactions may not necessarily be positive. For example, the inability to reciprocate help can threaten the recipient's self-esteem if it requires a person to admit impairment or conflicts with values of selfreliance and independence.

This cross-sectional study examined psychological predictors of adjustment to COPD. The hypothesis was that coping styles, self-efficacy and social support 
would influence adjustment to COPD. Adjustment was measured in terms of depression, anxiety and quality of life.

\section{Materials and method}

\section{Study subjects}

The 92 subjects had been inpatients and/or attended the outpatient clinic at the Concord Repatriation General Hospital (CRGH), Sydney, Australia, who satisfied the criteria and agreed to participate in the study. To be eligible for inclusion patients were: 1) male; 2) aged 40-80 yrs; 3) diagnosed as suffering from emphysema, and/or chronic bronchitis by a chest physician; 4) registering a prebronchodilator forced expiratory volume in one second (FEV1) $<80 \%$ predicted; 5) free from any other significant pulmonary disease (e.g. tuberculosis, fibrositis); 6) fluent in the English language; 7) free from any chronic disabling nonpulmonary disease that would confound results (e.g. insulin dependent diabetes, symptomatic cancer, chronic psychiatric illness, dementia). All patients gave informed consent as approved by the CRGH Ethics Committee.

\section{Method}

An appointment was made in the Outpatients' Department or at the subject's home where the questionnaires were read in randomized order to the subjects who verbally responded. It was decided that this would be the most consistent method as clinical experience has demonstrated that many elderly patients prefer to have questionnaires read to them. Subjects gave demographic information relating to age, duration of COPD, marital, physiological and socioeconomic status. Socioeconomic status was measured by the Prestige Scale of Daniel [9] that rates occupational status as a measure of power, privilege and prestige in Australian society. The scale provides category codes for the majority of Australian occupations.

\section{Study design}

Independent variables. The independent variables in the study are as follows:

Coping. The Coping with Illness Questionnaire (CWIQ) [10] was developed for this study as an appropriate standardized questionnaire to assess the coping strategies of the study population was not available. LAZARUS and FolKMAN [6] stress that the utility of any coping pattern varies with the type of encounter, the type of personality stressed and the outcome modality studied (e.g. subjective well-being, social functioning or somatic health). Thus, to investigate the coping strategies of people with COPD it was essential to use a questionnaire containing items that were pertinent to the symptoms of COPD.
The CWIQ lists 30 coping strategies and the subject is asked to indicate how often they use each of the strategies when they experience breathlessness, the major symptom of COPD. The CWIQ has four factors, and an example of a typical item from each factor follows: "Passive" - "I hope that a miracle will happen"; "Catastrophizing withdrawal" - "I feel that life is not worth living"; "Cognitive behavioural"- "I tell myself I can cope if I take things slowly"; and "Active distraction"- "I don't allow myself to pay attention to the problem". The internal consistency of the CWIQ was acceptable, the alpha coefficient for the item-total was 0.84 and for the factors ranging from $0.67-0.77$. The CWIQ showed appropriate concurrent validity with factors of the General Health Questionnaire (GHQ-30) [11].

Self-efficacy. The COPD Self-Efficacy Scale [12] rates the strength of expectations of managing or avoiding breathing difficulty in 34 situations. Scores are obtained in the domains of negative affect; intense emotional arousal; physical exertion; weather/ environment; and behavioural factors. Note that a low score indicates a high level of self-efficacy.

Social support. The Illness-Specific Social Support Scale (ISSS) [13] was developed for use with a population with Rheumatoid Arthritis (RA). As a standardized scale specific to COPD was not available, this scale was used, as the items were appropriate for a COPD population. Both RA and COPD are chronic illnesses with limitations in physical functioning with fluctuating symptoms. The scale rates how often the social network (family and friends) respond in different ways when individuals are not feeling well because of their illness. The scale provides two scores, a sum of the 19 positive, and a sum of the 18 problematic support items. The reliability coefficient for the Positive Support scale was 0.87 and for the Problematic Support scale 0.91.

Dependent variables. The dependent variables in the study are as follows:

Depression. The Beck Depression Inventory (BDI) [14] measures depressive symptoms experienced over the past week. The scores range from a minimum of zero to a possible maximum of 63. A patient with a total score of $\geqslant 15$ is considered to have significant depression [15]

Anxiety. The State Trait Anxiety Inventory (Form $\mathrm{X}-2$, trait anxiety) [16] was used to measure the level of anxiety "generally" felt, rather than the Form X-1, state anxiety which asks subjects to indicate how they "feel right now, that is, at this moment", to be more consistent with the BDI (how the subject has felt "over the past week" and the cyclical nature of depressive symptoms). The range of possible scores varies from a minimum score of 20 to a maximum of 80 . The mean normalized score for a male population aged $70-79$ yrs is 32.15 with an SD of 7.49 [17]. 
Table 1.-Descriptive statistics

\begin{tabular}{lc}
\hline Description of sample & \\
\hline Variable & \\
$\quad$ Age & $71 \pm 6$ \\
Duration of COPD yrs & $18 \pm 16$ \\
Quality of life: symptoms & $78.8 \pm 17$. \\
FEV1 & $37.3 \pm 18$ \\
Quality of life: total & $60.5 \pm 15$ \\
Socioeconomic status & \\
Professionals or middle-management & 8 \\
Skilled in both blue and white collar work & 44 \\
Semi-skilled to unskilled work & 14 \\
Less skilled manual and nonmanual work & 28 \\
\hline
\end{tabular}

Data are presented as mean \pm SD or percentage of sample. \#: high score=low quality of life. COPD: chronic obstructive pulmonary disease; FEV1: forced expiratory volume in one second.

Quality of life. The St. George's Respiratory Questionnaire (SGRQ) [18] has three sections relating to symptoms, activity and impact. Each of the three sections of the questionnaire and a summary score is scored separately in the range of $0-100 \%$, with a score of zero indicating no impairment of life quality. The SGRQ scores are calculated using weights attached to each item in the questionnaire. Note that a high score denotes a low quality of life. The symptom score was used in the multiple regression analysis as an indicator of severity of illness.

\section{Analysis}

Severity and duration of disease, age and previous occupation have been demonstrated to be of consequence in COPD [19-22], and were used as control variables in the regression analysis to avoid confounding the predictive power of the independent variables. The relationship between dependent variables (depression, anxiety and quality of life) and independent variables (coping strategies, self-efficacy and positive and negative social support) were first considered using
Pearson Product Moment correlation coefficients. As there were multiple comparisons, Bonferroni adjustments [23] were made when interpreting the data. To evaluate the predictive validity of the independent variables and the relationship between them, a series of hierarchical multiple regression analyses were performed.

\section{Results}

\section{Descriptive statistics}

Table 1 describes the sample, which was elderly, with a long duration of COPD and a poor physiological status. An FEV1 spirometry reading of $<80 \%$ pred is two standard deviations below the mean, which is considered abnormal [24]. Table 1 also indicates that the socioeconomic status of the sample is predominantly from the middle to lower end of the socioeconomic scale.

\section{Independent and dependent variables}

The means and standard deviations of the independent and dependent variables and their correlations are shown in table 2. It was noted that on average these subjects reported depression and anxiety scores within the normal range [15, 17]. Although their quality of life was reduced in terms of symptoms and activities, the impact of COPD on this sample was not generally severe.

Table 2 also shows that subjects who frequently used catastrophic withdrawal coping strategies experienced higher levels of depression and anxiety and a reduced quality of life. Subjects with low self-efficacy in symptom management reported higher levels of anxiety and more impaired quality of life. Finally, subjects who experienced more frequent negative social interactions showed higher levels of depression and anxiety. There were no other significant correlations between independent and dependent variables.

Table 2. - Means and standard deviations (SD) of the independent and dependent variables and their correlations

\begin{tabular}{|c|c|c|c|c|c|c|c|c|c|c|c|}
\hline Variable & $\mathrm{M} \pm \mathrm{SD}$ & $\begin{array}{l}\text { Passive } \\
\text { coping }\end{array}$ & $\begin{array}{l}\text { C/W } \\
\text { coping }\end{array}$ & $\begin{array}{l}\text { C/B } \\
\text { coping }\end{array}$ & $\begin{array}{l}\text { A/D } \\
\text { coping }\end{array}$ & $\begin{array}{l}\text { Self- } \\
\text { efficacy }\end{array}$ & $\begin{array}{l}\text { Positive } \\
\text { support }\end{array}$ & $\begin{array}{l}\text { Negative } \\
\text { support }\end{array}$ & Depr. & Anx. & $\begin{array}{l}\text { QOL } \\
\text { total }^{\oplus}\end{array}$ \\
\hline Passive Coping & $1.44 \pm 0.37$ & 1.00 & & & & & & & & & \\
\hline $\mathrm{C} / \mathrm{W}$ Coping & $1.55 \pm 0.41$ & 0.33 & 1.00 & & & & & & & & \\
\hline C/B Coping & $2.32 \pm 0.43$ & 0.29 & 0.22 & 1.00 & & & & & & & \\
\hline A/D Coping & $1.26 \pm 0.32$ & 0.22 & 0.10 & 0.19 & 1.00 & & & & & & \\
\hline Self-Efficacy: total ${ }^{\#}$ & $14.22 \pm 3.68$ & 0.25 & $0.46^{* * *}$ & $0.34 * * *$ & 0.24 & 1.00 & & & & & \\
\hline $\begin{array}{l}\text { Positive Social } \\
\text { Support }\end{array}$ & $3.99 \pm 0.75$ & 0.21 & -0.05 & 0.16 & -0.15 & 0.08 & 1.00 & & & & \\
\hline $\begin{array}{l}\text { Negative Social } \\
\text { Support }\end{array}$ & $1.59 \pm 0.50$ & 0.11 & 0.26 & 0.22 & 0.23 & 0.25 & -0.11 & 1.00 & & & \\
\hline Depression & $8.38 \pm 6.96$ & 0.19 & $0.50 * * *$ & 0.08 & 0.05 & 0.31 & -0.26 & $0.35^{* * *}$ & 1.00 & & \\
\hline Anxiety & $32.13 \pm 10.14$ & 0.18 & $0.57 * * *$ & 0.05 & 0.11 & $0.41 * * *$ & -0.23 & $0.40 * * *$ & $0.74 * * *$ & 1.00 & \\
\hline QOL total ${ }^{\top}$ & $60.49 \pm 15.20$ & 0.14 & $0.48 * * *$ & 0.30 & -0.04 & $0.55 * * *$ & -0.02 & 0.19 & $0.48 * * *$ & $0.37 * * *$ & 1.00 \\
\hline
\end{tabular}

Number of subjects=92. C/W: catastrophic withdrawal; C/B: cognitive behavioural; A/D: active distraction; QOL: quality of life; Depr.: depression; Anx.: anxiety. ${ }^{\#}$ : low score self-efficacy=high self-efficacy; ${ }^{\text {: }}$, high score=low QOL. ${ }^{* * *}$ : p<0.001, Bonferroni adjusted for multiple comparisons [23]. 
Table 3. - Adjustment of adjustment from coping

\begin{tabular}{|c|c|c|c|c|c|c|c|c|c|c|c|c|}
\hline \multirow[b]{2}{*}{ Predictor } & \multicolumn{4}{|c|}{ Depression } & \multicolumn{4}{|c|}{ Anxiety } & \multicolumn{4}{|c|}{ QOL Total Score } \\
\hline & $\mathrm{R}^{2}$ & $\begin{array}{c}\mathrm{R}^{2} \\
\text { change }\end{array}$ & $95 \% \mathrm{CI}$ & Beta & $\mathrm{R}^{2}$ & $\begin{array}{c}\mathrm{R}^{2} \\
\text { change }\end{array}$ & $95 \% \mathrm{CI}$ & Beta & $\mathrm{R}^{2}$ & $\begin{array}{c}\mathrm{R}^{2} \\
\text { change }\end{array}$ & $95 \%$ CI & Beta \\
\hline \multicolumn{13}{|l|}{ Step 1} \\
\hline QOL Symptoms & & & $-0.05-0.11$ & 0.07 & & & $-0.12-0.10$ & -0.01 & & & & \\
\hline Occupation & & & $-0.20-2.30$ & 0.16 & & & $-0.28-3.20$ & 0.15 & & & $0.93-6.12$ & $0.24 *$ \\
\hline Duration & & & $-0.14-0.03$ & -0.12 & & & $-0.18-0.06$ & -0.10 & & & $-0.17-0.18$ & 0.01 \\
\hline Age & & & $-0.24-0.20$ & -0.02 & & & $-0.24-0.36$ & 0.04 & & & $-0.69-0.20$ & -0.10 \\
\hline \multirow{2}{*}{\multicolumn{13}{|c|}{$\begin{array}{l}\text { Step } 2 \\
\text { Coping }\end{array}$}} \\
\hline & & & & & & & & & & & & \\
\hline Passive & & & $-3.15-4.48$ & 0.04 & & & $-5.33-5.26$ & -0.00 & & & $-10.35-5.46$ & 0.06 \\
\hline $\begin{array}{l}\text { Catastrophic } \\
\text { Withdrawal }\end{array}$ & & & $4.41-11.35$ & $0.46^{* * *}$ & & & $9.11-18.74$ & $0.56^{* * *}$ & & & $9.17-23.23$ & $0.43^{* * *}$ \\
\hline $\begin{array}{l}\text { Cognitive } \\
\text { Behavioural }\end{array}$ & & & $-3.59-2.98$ & -0.02 & & & $-5.87-3.25$ & -0.06 & & & $1.60-15.09$ & 0.24 \\
\hline $\begin{array}{l}\text { Active } \\
\text { Distraction }\end{array}$ & & & $-4.37-4.01$ & -0.01 & & & $-3.54-8.09$ & 0.07 & & & $-14.47-2.94$ & -0.12 \\
\hline F Equation & 0.30 & $\begin{array}{r}0.20^{* * *} \\
\mathrm{~F}(8,83)=\end{array}$ & $=4.45, \mathrm{p}<0.0$ & & 0.36 & $\begin{array}{c}0.29 * * * \\
\mathrm{~F}(8,83)=\end{array}$ & $=5.96, p<0.0$ & & 0.36 & $\begin{array}{r}0.26 * * * \\
\mathrm{~F}(7,84)\end{array}$ & $=6.73, \mathrm{p}<0.00$ & \\
\hline
\end{tabular}

Number of subjects=92. QOL: quality of life; CI: confidence interval. ${ }^{\#}$ : High score=low QOL. Beta values computed when all values were in the equation. QOL symptom sub-scale was used as the measure for severity of disease. This sub-scale was not included in prediction of QOL Total Score, which includes the symptom sub-scale. ${ }^{*}: \mathrm{p}<0.05 ;{ }^{* *}: \mathrm{p}<0.01 ; * * *: \mathrm{p}<0.001$.

\section{Coping}

Table 3 indicates that after controlling for demographic and illness severity factors, the measures of coping, when entered together in the same step into the regression analyses, contributed significantly to the prediction of depression, anxiety, and quality of life. Of the specific forms of coping, only catastrophic withdrawal coping contributed significantly to the prediction of depression, anxiety and a more impaired quality of life. (Note that higher quality of life scores denote greater impairment). As such, individuals who tended to report greater use of catastrophic withdrawal forms of coping were more likely to experience higher levels of depression and anxiety and a lower quality of life.

\section{Self-efficacy}

Table 4 shows that after entering the control variables, lower levels of self-efficacy to manage or avoid breathing difficulties predicted higher levels of depression, anxiety and a more impaired quality of life. (High scores on the self-efficacy scale denote lower levels of self-efficacy).

\section{Social support}

Table 5 evidences that after entering the control variables, high levels of positive social support predicted lower levels of depression and anxiety, while higher levels of negative social support predicted

Table 4. - Adjustment of adjustment from self-efficacy

\begin{tabular}{|c|c|c|c|c|c|c|c|c|c|c|c|c|}
\hline \multirow[b]{2}{*}{ Predictor } & \multicolumn{4}{|c|}{ Depression } & \multicolumn{4}{|c|}{ Anxiety } & \multicolumn{4}{|c|}{ QOL Total Score } \\
\hline & $\mathrm{R}^{2}$ & $\begin{array}{l}\mathrm{R}^{2} \\
\text { change }\end{array}$ & $95 \% \mathrm{CI}$ & Beta & $\mathrm{R}^{2}$ & $\begin{array}{l}\mathrm{R}^{2} \\
\text { change }\end{array}$ & $95 \% \mathrm{CI}$ & Beta & $\mathrm{R}^{2}$ & $\begin{array}{c}\mathrm{R}^{2} \\
\text { change }\end{array}$ & $95 \% \mathrm{CI}$ & Beta \\
\hline \multicolumn{13}{|l|}{ Step 1} \\
\hline QOL Symptoms & & & $-0.05-0.12$ & 0.08 & & & $-0.15-0.10$ & -0.04 & & & & \\
\hline Occupation & & & $-0.30-2.46$ & 0.16 & & & $-0.66-3.22$ & 0.13 & & & $0.06-5.28$ & $0.18^{*}$ \\
\hline Duration & & & $-0.15-0.03$ & -0.13 & & & $-0.20-0.05$ & -0.11 & & & $-0.11-0.23$ & 0.06 \\
\hline Age & & & $-0.26-0.21$ & -0.02 & & & $-0.29-0.37$ & 0.02 & & & $-0.71-0.15$ & -0.11 \\
\hline & 0.10 & 0.10 & & & 0.07 & 0.07 & & & 0.10 & $0.10^{*}$ & & \\
\hline $\begin{array}{l}\text { Step } 2 \\
\text { Self-Efficacy }\end{array}$ & & & $0.04-0.88$ & $0.24^{*}$ & & & $0.50-1.68$ & $0.40^{* * *}$ & & & $1.38-2.85$ & $0.51 * * *$ \\
\hline F Equation & \multicolumn{4}{|c|}{$\mathrm{F}(5,86)=2.87, \mathrm{p}<0.05$} & \multicolumn{4}{|c|}{$\mathrm{F}(5,86)=4.28, \mathrm{p}<0.01$} & \multicolumn{4}{|c|}{$\mathrm{F}(4,87)=11.66, \mathrm{p}<0.001$} \\
\hline
\end{tabular}

$\mathrm{N}=92$. QOL: quality of life; CI: confidence interval. \# : High score=low QOL; ${ }^{\text {: }}$ low score self-efficacy=high self-efficacy. Beta values computed when all values were in the equation. QOL symptom sub-scale was used as the measure for severity of disease. This sub-scale was not included in prediction of QOL Total Score, which includes the symptom sub-scale. *: p<0.05; $* *: \mathrm{p}<0.01 ; * * *: \mathrm{p}<0.001$ 
Table 5. - Adjustment of adjustment from social support

\begin{tabular}{|c|c|c|c|c|c|c|c|c|c|c|c|c|}
\hline \multirow[b]{2}{*}{ Predictor } & \multicolumn{4}{|c|}{ Depression } & \multicolumn{4}{|c|}{ Anxiety } & \multicolumn{4}{|c|}{ QOL total score } \\
\hline & $\mathrm{R}^{2}$ & $\begin{array}{l}\mathrm{R}^{2} \\
\text { change }\end{array}$ & $95 \% \mathrm{CI}$ & Beta & $\mathrm{R}^{2}$ & $\begin{array}{l}\mathrm{R}^{2} \\
\text { change }\end{array}$ & $95 \% \mathrm{CI}$ & Beta & $\mathrm{R}^{2}$ & $\begin{array}{l}\mathrm{R}^{2} \\
\text { change }\end{array}$ & $95 \% \mathrm{CI}$ & Beta \\
\hline \multicolumn{13}{|l|}{ Step 1} \\
\hline QOL Symptoms \# & & & $-0.01-0.14$ & 0.16 & & & $-0.06-0.16$ & 0.09 & & & & \\
\hline Occupation & & & $0.16-2.67$ & 0.21 & & & $0.21-3.83$ & $0.21 *$ & & & $1.37-7.28$ & 0.05 \\
\hline Duration & & & $-0.15-0.01$ & -0.16 & & & $-0.21-0.03$ & -0.15 & & & $-0.15-0.24$ & $0.29 * *$ \\
\hline Age & & & $-0.12-0.33$ & 0.11 & & & $-0.02-0.62$ & 0.18 & & & $-0.63-0.42$ & -0.04 \\
\hline & 0.10 & 0.10 & & & 0.07 & 0.07 & & & 0.10 & $0.10^{*}$ & & \\
\hline \multicolumn{13}{|l|}{ Step 2} \\
\hline $\begin{array}{l}\text { Positive Social } \\
\text { Support }\end{array}$ & & & $-4.00-0.54$ & $-0.25^{* *}$ & & & $-5.17--0.19$ & $-0.20 *$ & & & $-4.26-3.91$ & -0.01 \\
\hline $\begin{array}{l}\text { Negative Social } \\
\text { Support }\end{array}$ & & & $1.66-7.16$ & $0.32 * *$ & & & $4.37-12.28$ & $0.41 * * *$ & & & $-1.13-11.83$ & 0.18 \\
\hline F Equation & 0.26 & $\begin{array}{l}0.17 * * * \\
\mathrm{~F}(6,85)=\end{array}$ & $=5.10, \mathrm{p}<0.0$ & & 0.28 & $\begin{array}{r}0.21 * * * \\
\mathrm{~F}(6,85)\end{array}$ & $=5,61, \mathrm{p}<0.0$ & & 0.13 & $\begin{array}{l}0.03 \\
F(5,86)\end{array}$ & $=2.57, p<0.2$ & \\
\hline
\end{tabular}

$\mathrm{N}=92$. QOL: quality of life; $\mathrm{CI}$ : confidence interval. ${ }^{*}$ : High Score=low QOL. Beta values computed when all values were in the equation. QOL symptom sub-scale was used as the measure for severity of disease. This sub-scale was not included in prediction of QOL Total Score, which includes the symptom sub-scale. *: $\mathrm{p}<0.05 ; * *: \mathrm{p}<0.01 ; * * *: \mathrm{p}<0.001$.

higher levels of depression and anxiety. Neither high levels of positive nor negative social support predicted quality of life.

\section{Discussion}

This study supports the hypothesis that psychological factors, namely coping, self-efficacy of symptoms management and social support, play an important role in optimizing adjustment in terms of depression, anxiety and quality of life. Higher levels of catastrophic withdrawal coping strategies and lower levels of self-efficacy of symptom management were associated with higher levels of depression, anxiety and a more impaired quality of life. Higher levels of positive support were linked to lower levels of anxiety and depression, while lower levels of negative support were linked to higher levels of depression and anxiety.

Overall, this sample had a poor physiological status, a moderately impaired quality of life and was more anxious than depressed. The sample was not within the clinical range of depression or anxiety. It is difficult to ascertain why this sample was not more depressed or anxious given the severity of their illness. However, this sample was all male and of all the factors studied in prior research, being female has most clearly been identified with a higher prevalence of depressive symptoms [25].

The mean quality of life total score suggested a lower quality of life for the present sample than that reported in a previous study [26]. This may reflect the greater impairment of airflow of participants in the present study than that reported in the previous study [26]. Clearly, the participants in the present sample were significantly impaired by their illness.

Studies of reactions to illness have found that reactions differ with age and that older people anticipate illness as a predictable late-life stressor [27]. Health-related stressors may not produce the same reactions in the elderly although the effects can be just as devastating. The present sample was slightly older than samples used in other studies [26], and this may explain the relatively lower depression and anxiety scores in this illness sample.

\section{Coping and adjustment to chronic obstructive pulmonary disease}

The literature on coping and chronic illness led to hypotheses regarding the effect of coping strategies on adjustment to COPD. Correlational and multiple regression analyses indicated that high levels of catastrophic withdrawal coping predicted high levels of depression, anxiety and impaired quality of life. These results support the hypotheses and add to the existing knowledge of the role of coping to adjustment in COPD [3]. It is demonstrated that a specific component of coping, catastrophic withdrawal coping, influences outcome in COPD in terms of depression, anxiety and impaired quality of life.

Research has suggested some confounding between catastrophic withdrawal as a coping strategy or as a symptom of depression [28]. Three items on the CWIQ ("I cry"; "I seek sympathy from others"; and "I get angry with others") may have been confounded with depression and influenced results. However, given the relative consistency of the finding relating to the impact of catastrophic withdrawal coping upon other aspects of adjustment such as anxiety and quality of life, this proposition seems unlikely to explain the present results.

\section{The relationship of self-efficacy to adjustment in chronic obstructive pulmonary disease}

It was proposed that high levels of self-efficacy of symptom management would be associated with low 
levels of depression, anxiety and a less impaired quality of life in COPD patients. Correlational and multiple regression analyses evidenced that subjects with high self-efficacy in symptom management reported lower levels of depression, anxiety and less impaired quality of life. Previous research has demonstrated that self-efficacy is an important variable in physical performance [4] and these results indicate that self-efficacy is important in psychosocial adjustment to COPD.

\section{The relationship of social support to chronic obstructive pulmonary disease}

As predicted, higher levels of positive social support and lower levels of negative interaction were associated with lower levels of depression and anxiety. Previous research [5] found that COPD patients who were dissatisfied with their social relationships were likely to be lonely and depressed. This study supported that finding, in that higher levels of positive social support predicted lower levels of depression. The negative aspects of social support were also investigated and added to previous information regarding negative aspects of social support. Until recently, the negative aspects of social support have been relatively ignored in research. REVENSON and SCHIAfFINo [13], in the development of the ISSS with RA patients, found that higher levels of problematic support were related to higher levels of depression. In the present research, multiple regression analyses indicated that more frequent negative interactions were associated with higher levels of depression and anxiety.

This study is cross-sectional and as such, causal inferences cannot be drawn from the study. It may well be that depression causes the patients to respond more negatively on self-report scales of social support, to report more catastrophizing thoughts and less confidence in the management of their breathlessness. The relationship of coping, self-efficacy and social support to adjustment to COPD is explored within the framework of the theory of LAZARUS and FOLKMAN [6]. This theory posits that the process of appraisal would be a continual process and COPD as a chronic illness constitutes an ongoing stressor. This crosssectional study does not entirely capture this model, as it examined only a slice of this ongoing process. However, the results demonstrate that this more traditional methodology is a useful basis for research.

As the sample was elderly, male, with the subjects predominantly from the middle to lower end of the socioeconomic scale, and patients of a metropolitan public hospital, the results may not generalize to other populations (for example, females, more affluent patients of a private hospital or rural populations).

As physical status is being medically stabilized, psychological factors need to be carefully assessed. Psychological interventions should focus on the introduction of psychological techniques to decrease catastrophic withdrawal coping strategies, to raise levels of self-efficacy of symptom management and to cope with the inevitable negative interactions encountered. This, in turn, could increase the quality of life for this debilitated patient population. Future research should apply the knowledge that has been gained from this research in a controlled and evaluated treatment programme.

\section{References}

1. Yohannes AM, Baldwin RC, Connolly MJ. Depression and anxiety in elderly outpatients with chronic obstructive pulmonary disease: prevalence, and validation of the BASDEC screening questionnaire. Int $J$ Geriatr Psychiatry 2000; 15: 1090-1096.

2. Stavem K, Lossius MI, Kvien TK, Guldvog B. The health-related quality of life of patients with epilepsy compared with angina pectoris, rheumatoid arthritis, asthma and chronic obstructive pulmonary disease. Qual Life Res 2000; 9: 865-871.

3. Narsavage GL, Weaver TE. Physiologic status, coping and hardiness as predictors of outcomes in chronic obstructive pulmonary disease. Nurs Res 1994; 43: 90-94.

4. Rejeski WJ, Foley KO, Woodward CM, Zaccaro DJ, Berry MJ. Evaluating and understanding performance testing in COPD patients. $J$ Cardiopul Rehab 2000; 20: 79-88.

5. Keele-Card G, Foxall MJ, Barron CR. Loneliness, depression and social support of patients with COPD and their spouses. Public Health Nurs 1993; 10: 245251.

6. Lazarus RS, Folkman S. Stress, appraisal and coping. New York, Springer Publishing Group, 1984.

7. Bandura A. Self-efficacy mechanism in human agency. Am Psychol 1982; 37: 122-147.

8. Shumaker SA, Brownell A. Toward a theory of social support: Closing conceptual gaps. J Soc Issues 1984; 40: 11-13.

9. Daniel A. Power, privilege and prestige: occupations in Australia. Melbourne, Australia, Longman Cheshire, 1983.

10. McCathie HCF. Investigation of the coping strategies of individuals suffering from chronic respiratory disease. Sydney, Australia, University of Sydney, 1998 (PhD thesis).

11. Goldberg DP. The detection of psychiatric illness by questionnaire: a technique for the identification and assessment of non-psychotic psychiatric illness. London, Oxford University Press, 1972.

12. Wigal K, Creer TL, Kotses H. The COPD self-efficacy scale. Chest 1991; 99: 1193-1196.

13. Revenson TA, Schiaffino KM. Development of a contextual social support measure for use with arthritis populations. Paper presented at the annual convention of the Arthritis Health Professions Association. Seattle, WA, 1990.

14. Beck AT, Ward $\mathrm{CH}$, Mendelson $\mathrm{M}$, et al. An inventory for measuring depression. Arch Gen Psychiatry 1961; 4: 561-571.

15. Nielsen AC III, Williams TA. Depression in ambulatory medical patients: Prevalence by self-report questionnaire and recognition by non-psychiatric physicians. Arch Gen Psychiatry 1980; 37: 999-1004.

16. Spielberger DC, Gorsuch RC, Lushene RE. Manual for the state-trait anxiety inventory. Palo Alto, Consulting Psychologists Press, 1970. 
17. Knight RG, Waal-Manning HJ, Spears GF. Some norms and reliability data for the State Trait Inventory and the Zung Self Rating Depression Scale. $\mathrm{Br}$ $J$ Clin Psych 1983; 22: 245-249.

18. Jones PW, Quirk FH, Baveystock CM. The St. George's Respiratory Questionnaire. Respir Med 1991; 85: Suppl. B, 25-31.

19. McSweeney AJ, Grant I, Heaton RK, et al. Life quality of patients with chronic obstructive pulmonary disease. Arch Int Med 1982; 12: 473-478.

20. Prigitano GP, Parsons O, Wright E, et al. Neuropsychological test performance in mildly hypoxemic patients with chronic obstructive pulmonary disease. $J$ Consult Clin Psychol 1983; 51: 108-116.

21. Nocturnal Oxygen Therapy Trial Group. Continuous or nocturnal oxygen therapy in hypoxemic chronic obstructive lung disease. Ann Intern Med 1980; 93: 391-398.

22. Clarke SW. Chronic bronchitis in the 1990's: up-todate treatment. Respiration 1991; 58: Suppl. 1, 43-46.

23. Bird K, Hall W. The problem of multiple inference in psychiatric research. Aust NZ J Psychiatry 1985; 19: 265-274.

24. Dockery DW. Percentile curves for evaluation of repeated measures of lung function. Occupat Med 1993; 8: 323-338.

25. Gutierrez-Lobos K, Woelfl G, Scherer M, Anderer P, Schmidl-Mohl B. The gender gap in depression reconsidered: The influence of marital and employment status on the female/male ratio of treated incidence rates. Soc Psychiatry Psychiatric Epidemiol 2000; 35: 202-210.

26. Jones PW, Quirk FH, Baveystock CM, et al. A self-complete measure of health status for chronic airflow limitation. Am Rev Respir Dis 1992; 145: 31211327.

27. Lazarus RS, DeLongis A. Psychological stress and coping in aging. Am Psychol 1983; 38: 245-254.

28. Stanton AL, Danoff-Burg S, Cameron CL, et al. Coping through emotional approach: Problem of conceptualization and confounding. J Pers Soc Psychol 1994; 66: 350-362. 